\title{
REHÚSO, SEÑOR PRESIDENTE
}

Daniela L. Guzmán*

\begin{abstract}
Puede que los diputados hayan cometido un error al volver a permitir la reelección presidencial en la República Mexicana.

Durante el debate previo, mucho se analizó acerca de por qué el pueblo mexicano les temía a los reelectos. Se pensó que se trataba de miedo a la repetición infinita, a la copia, a la suplantación inadvertida de una cosa por otra que se le parece demasiado - ¿qué es el envejecimiento (el envejecimiento de un mandatario) sino una forma suprema de la suplantación?

El mexicano, entonces, prefiere el alivio de ser gobernado por una serpiente de cabezas intercambiables. A veces la serpiente se pone una cabeza de caballo o una cabeza de tetrapack de jugo de naranja. No importa. El consuelo está en el cambio. Nulo, cosmético, pero cambio.

Cuando el cambio dejó de persistir, sin embargo, y el señor Díez - un hombre que, ya en el jardín de infancia, les decía a las educadoras que no lo pusieran a colorear tortugas porque él quería ser presidente y los presidentes no pierden el tiempo iluminando dibujitos - se reeligió para su segundo periodo, comenzaron a ocurrir cosas terribles.

La corrupción se detuvo, por ejemplo.

* Gabriela L. Guzmán (Guadalajara, 1991) fue beneficiaria del PECDA Jalisco y del FONCA en la categoría de cuento. Es autora de Noche de pizza con mi villano (Editorial Dreamers, 2019), del que se desprende "Rehúso, señor presidente". Obtuvo el Premio Nacional de Cuento Jesús Amaro Gamboa 2018.
\end{abstract}


El desgajamiento ocurrió una mañana en la que Justina Sierra, su secretaria particular, le comentó al presidente que un periódico de circulación nacional quería sacar a la luz no sé qué documentos que hablaban acerca de unas propiedades adquiridas en Miami con los fondos de la última campaña.

Díez, como de costumbre, le pidió a su secretaria llamar y ofrecerle al director del periódico una suma decorosa. Al día siguiente, sin embargo, aparecieron en primera plana las palmeras verdes, el sol de Florida y el titular que comunicaba los deslices monetarios del presidente.

_ ¡Justina! ¿No le dije que se ocupara de esta vergüenza?

La secretaria se plantó delante de él con las manos lánguidas, pulpos exangües sobre el fondo gris de su faldita lápiz. Le dijo, con un tono de sagaz indiferencia:

—Ah, sí, señor. Llamé, pero los del periódico rehusaron.

- ¿Rehusaron?

-Sí, rehusaron.

Al principio fue solo un periódico el que rehusó. Pronto fueron cinco, doce, ochenta. Rehusar. Algunos decían que era el nuevo verbo de moda para los periodistas, y ese es el hobby de todo reportero: inventarse bodrios verbales y repetirlos hasta el hartazgo, pero este bodrio era serio porque pronto se contagió a los banqueros y a los empresarios.

"Señor constructor, ¿qué le parecería recibir una concesión para construir una nueva carretera a cambio de su incondicional apoyo político?"

—Lo siento, señor. Rehúso.

"Rehúso, rehúso." Nadie, mucho menos el presidente, sabía si las negativas se debían a la honestidad o a un inusitado amor por la parálisis.

— ¿Puede explicarme cuál es la lógica de esta situación, Justina? —El presidente se hundía en su escritorio, debajo de papeles y papeles que constituían la documentación de iniciativas que se habían quedado estancadas, de repente. Justina le decía, sin embargo, que no se preocupara.

- Todo estará bien, señor presidente — susurraba en un tono aséptico- Alégrese, más bien, porque la Campaña Anticorrupción que implementamos el sexenio pasado ha dado sus frutos. 
En vano le decía el presidente que la campaña debía haber sido — como todas las campañas - una faramalla bonita, unos spots publicitarios cursis orientados a la obtención de unos exiguos (cuando no nulos) resultados.

-Pues tenga más cuidado con las medidas que me pide implementar, señor - le recordaba Justina-. Usted sabe que soy una secretaria eficiente.

Y tenía razón. Desde las cinco de la mañana estaba siempre Justina caminando por todas partes sin apenas doblar las rodillas, siempre moviéndose en línea recta, con su melena negra y su piel tirante. Díez nunca la vio encorvarse de la espalda. Diligente, Justina resolvía todos sus asuntos con eficiencia y en sus manos quedaba resuelta la gran mayoría de sus quehaceres presidenciales.

No había nada que no pudiera pedirle a Justina, pero conllevaba cierto absurdo pedirle ahora que implementara una Campaña ProCorrupción para contrarrestar la situación de rehusamientos imperante. Quién sabe si unos spots publicitarios que dijeran: “¡No rehúses! Tu felicidad tiene un precio y lo sabes, ¡véndete!" habrían servido para aliviar el acuciante problema de la parálisis.

En realidad, el estado natural de los grupos de interés de una nación - y de todos los hombres - es la parálisis. El soborno es una ignición, un motivo, la chispa divina que pone a los mundos en marcha. Los libros de autoayuda hablan de autosoborno, de autorrecompensa. Ningún cavernícola se habría atrevido a cazar un mamut de no ser por el autosoborno futuro de vestir la piel del mamut y comerse su carne; de lo que se sigue que la evolución humana ha estado siempre motivada por el soborno.

Heráclito mismo fue el primer apólogo del soborno como forma de vida. Tanta insistencia en el movimiento, en el flujo. La corrupción es puro flujo. La honradez, en cambio, es la parálisis del espíritu.

Así que un país que se vuelve honesto se paraliza. O eso fue lo que se dijo el presidente Díez para explicarse el fenómeno de los rehusantes.

En una ocasión, el presidente quiso construir una nueva línea de ferrocarril. Envió emisarios que ofrecían incentivos a los empresarios 
ferrocarrileros; les prometió a los ambientalocos que, si dejaban de protestar por la destrucción de algunos hábitats, aumentaría las leyes para proteger a las ballenas en Baja California; les prometió tierras de primera calidad a algunas comunidades indígenas que no deseaban desalojarse.

Pero los ferrocarrileros dijeron: "Rehúso", los ambientalocos dijeron: "Rehúso" y los indígenas también dijeron: "Rehúso".

Los emisarios no dijeron qué había en los ojos de los que rehusaban. ¿Era la llama fanática de la honradez? ¿Era la grisura, los paisajes agónicos de la parálisis?

De cualquier modo, su voluntad era inamovible y, como todas las voluntades inamovibles incitan al martirio, el presidente se vio obligado a encontrar una solución efectiva. Decidió mover al país acarreándolo con la tuneladora de las represiones violentas.

Dándose un resignado masaje en las sienes, Díez comenzó a decirle a Justina:

—Dé la orden al ejército de arremeter contra los indígenas. Haga que la policía le dé una calentadita a los ferrocarrileros. Encarcélese a varios de los ambientalocos.

- Como usted guste, señor presidente - le respondía Justina apretando sus folders contra el pecho.

110 Y no es que a Díez le encantara ser un hombre violento, al contrario. Siempre había pensado en sí mismo como un hombre generoso. Amigo de la zanahoria, moderado con el uso del garrote. Pero el látigo del desprecio concita el uso del látigo de la tortura, de las represiones de manifestantes y hasta el de los toques de queda.

Las cárceles se llenaron tan rápido de abúlicos presos políticos que, en un efluvio de creatividad sorpresiva, Justina le sugirió al presidente Díez que abrieran las prisiones a la iniciativa privada y las convirtieran en empresas.

— ¿Ve cómo le dije que todo estaría bien, señor presidente? —Justina sonreía con una mueca rectilínea, una especie de gesto que de seguro aparecería en los catálogos de aberraciones geométricas - ¡ ¡Ahora hasta estamos engrosando el presupuesto!

Al presidente Díez, en cambio, el asunto no lo tenía del todo satisfecho. Se dirá que los genocidas no conocen la culpa - y casi nunca la 
conocen - pero, algunas noches, Díez se imaginaba que había en cierta esquina de su alcoba — en un confuso ángulo que se formaba entre el armario y una mesita de noche - algo que podía matarlo.

No era un hombre, por supuesto. A veces Díez tenía la impresión de que se trataba de un insecto, un insecto gigante e inflamado. Pero tampoco era un insecto. O tal vez se tratase de un objeto común. Un lápiz, un pisapapeles, una licuadora.

Y Díez entonces pensaba que la anomalía no era que la voluntad del país - de todos los rehusantes - se hubiera muerto, sino que se había transferido a ese objeto común en el que estaba creciendo, apilándose. Quizás esa voluntad había dejado de querer otras cosas porque lo que quería era eso: matarlo.

El presidente le transmitía sus preocupaciones a Justina a veces como un huérfano, otras con un temblor en la mano, mientras a Justina le brillaba el pelo con un fulgor sideral. Le decía que qué tal si tanta represión despertaba el odio hacia su régimen. Qué tal si nadie votaba por él en las próximas elecciones.

- Nadie lo odia — decía Justina, desplegando su sonrisa rectilínea y uniformemente acelerada— - Todo estará bien, señor presidente.

Y, en cierto sentido, todo estaba bien: el Producto Interno Bruto crecía como nunca, la deuda externa se pagaba, los destinos turísticos habían remontado, todos los mexicanos tenían empleo - precario, pero al fin empleo. El país hasta se había dado el lujo de atraer inversión japonesa para montar un tren bala que conectaría Monterrey, Guadalajara y las ciudades importantes del Valle de México.

Pero había ocasiones en las que Díez temía incluso asomarse a las ventanas.

- ¿Qué tal si me matan, Justina? — deliraba el presidente.

Justina le reafirmaba que todo estaría bien, le servía un trago de coñac, y le decía que la gente lo amaba de verdad.

-Mire, vamos a dar un paseo para que se tranquilice.

Y, saltándose todos los estatutos del Estado Mayor Presidencial, Justina se llevaba al presidente a dar una vuelta por Chapultepec, por el Zócalo, por Donceles, Tacuba y esos sitios donde a uno solían fabricarle documentos falsificados, solo que ya no los hacían: el reino de la Honestidad Total los había vuelto inoperantes. 
— ¿Lo ve, señor presidente?

Y la gente lo veía pasar y extendía la mano para embadurnarse con el sudor de sus pantalones Armani. Se inclinaban ante él como ante un santo o ante un pontífice. Le sonreían con sus caras de soles ardientes.

Nadie intentó matarlo durante sus caminatas.

Y así fue cómo el presidente Díez vio que sus temores eran vanos.

La voluntad del país no estaba concentrándose en ningún sitio para saltarle de pronto y matarlo. La voluntad del país se había estado replegando durante todo el sexenio para, de pronto, acometer la hazaña de reelegirlo para un tercer periodo con el ciento cuarenta por ciento de los votos.

Justina decía que había gente tan fanática que desafiaba el sistema electoral y votaba dos veces con tal de garantizar su perpetuación en la presidencia.

-Usted gobernará durante mil años, señor presidente.

Y Díez no entendía cómo el fanatismo podía arrasarlo todo. Cómo esa gente podía votar dos veces por él cuando casi no había nadie en todo el país que no tuviera un familiar encarcelado, desaparecido o forzado a trabajar sin paga en las salinas de Baja California.

— Justina — al presidente le faltaba el aire — , toda esta gente... es adicta al abuso, ¿o qué?

Díez pensaba que tal vez la abulia los trastornaba. Quizás la represión les martillaba la carne, pero sus cuerpos se rehusaban a sangrar.

- No piense en eso. Piense en lo bueno, señor presidente — lo atajaba Justina.

Y pensaba en lo bueno. Pero un día, a los pocos meses de su segunda reelección, Díez emitió una orden de matar en caliente a unos huelguistas que se manifestaban en Puebla. Exigían — cosa rara que alguien pudiera exigir en aquellos tiempos tan morigerados- la restitución de sus derechos laborales.

Díez recibió la respuesta inmediata de parte de sus cuerpos represivos:

"Gracias por la orden, señor presidente. Nos rehusamos a cumplirla, sin embargo. Saludos cordiales."

Y "Nos rehusamos a cumplir sus órdenes. Saludos cordiales" fue todo lo que el ejército, las policías federales, locales y hasta la secreta le comunicaron a partir de aquel entonces. 
Díez los exhortó: “¿Qué no les importa el país?”. Intentó destituir a los altos mandos de las fuerzas del orden y sustituirlos por subalternos más o menos capaces. Todos los subalternos le dijeron: "No, señor, discúlpeme. Rehúso el nombramiento. Saludos cordiales". Y pronto, incluso dejó de recibir aquellos lánguidos memorándums.

Nadie volvió a ver jamás a un policía ni a un militar caminando sobre las vastedades del territorio mexicano.

El presidente se preguntaba si sus cuerpos represivos se habrían vaporizado o si más bien se habrían recluido en la oscuridad de sus cuarteles, plastificándose de abulia para esperar el olvido o el fin de los tiempos. No lo supo. Tampoco supo qué mecanismo convierte la lealtad en indiferencia pero, a partir de entonces, no soportó que se dijeran delante de él las palabras "ejército", "policía" o "cuarteles".

Díez empezó a preguntarse si eran ciertos los temores de los mexicanos. Quizás cada reelección engendrase una copia cada vez inferior, más imprecisa de las realidades nacionales. Se imaginó el fin del país convertido en una transparencia, en el trazo torpe de un niño que dibuja el mapa de México en un pliego de papel albanene.

- No pasa nada, señor presidente - le decía Justina con su sonrisa de mármol negro - . Todo estará bien, ya se lo digo.

Y era cierto. No pasaba nada. La parálisis del país acabó por ser incurable. Sin la tuneladora de la represión, el presidente no pudo nunca más reformar ni una ley ni construir la más mínima de las obritas públicas, y fue el gobierno quien se convirtió en el paralítico.

Como la inmovilidad es lo mismo que el movimiento aparente, de la sociedad comenzó a surgir el brío de la actividad inútil, incesante. Manifestantes emergían de todas partes para quejarse de la falta de autoridad, del gobierno inoperante, de tanta represión y tanta sangre que, por obra de un milagro, recordaban.

Nada pudo detenerlos.

Hordas de manifestantes arrasaban el país desde Tijuana hasta Mérida, como bisontes armados con pancartas que decían: “¡Fuera el tirano! ¡Sufragio efectivo no reelección!”.

Y, sin embargo, en los mítines y en los actos públicos la multitud seguía aclamándolo. La gente vestía playeras estampadas con la cara 
de general prusiano del presidente Díez. Algunos incluso se dejaban crecer el bigote para parecerse al amadísimo gobernante.

— ¿Ve cómo la gente sigue amándolo, señor presidente? ¿Ve cómo le dije que todo estaría bien?

Pero a Díez dejó de preocuparle el amor. Ahora le preocupa que a veces mira a las multitudes $y$, no sabe si es el cansancio borroso que se le acumula en la vista — el cansancio de no hacer nada - ; no sabe si es porque viaja mucho, porque el frenesí de convenciones, giras y cumbres económicas no ha terminado desde su primera campaña política, pero en ocasiones siente que la gente que lo aclama en realidad no está ahí. Los mira agitar los brazos y detrás de ellos ve los números sin fin de una secuencia programada por computadora. Un ordenador cuenta, produce a toda esta gente durante la noche, se le ocurre. El país es una anomalía del sistema. A veces el presidente se imagina el relojito de Windows encima de su cabeza, dando vueltas mientras la realidad todavía no termina de coagularse.

Ya no piensa en eso que está en la esquina de su alcoba, ya no piensa que puedan matarlo. Quien se perpetúa en el poder aguarda en secreto la indulgencia del magnicidio, del golpe de Estado. Díez ya no la aguarda. Ahora piensa — sabe - que la realidad es un despojo, que el país es la cáscara de una naranja que se resiste a pudrirse.

— ¿Qué es esta locura, Justina? — le pregunta a veces al borde de la psicosis o del paroxismo.

Justina ya no le responde. Transcurre un sexenio de tiempo gris, y un día, aunque ya no se postula, Díez consigue reelegirse para un cuarto periodo con el ciento noventa por ciento de los votos.

Todos votaron por él en la casilla de "Otros candidatos" y Justina le dice que cada vez hay más personas dispuestas a votar dos o hasta tres veces con tal de que Díez nunca abandone la residencia de Los Pinos.

Desde una silla de playa, en el balcón en el que Díez aguardaba con indiferencia los resultados de los comicios, el presidente le dice a Justina:

-Máteme, Justina.

Le extiende un revólver. Está cargado. 
— ¡Máteme! Yo no sé qué le hicimos a México, pero esto ya no es un país. Es una aberración. ¿Qué espera? ¡Máteme!

Justina lo mira de pie, con su rectitud de hormiga eterna. Lo mira y le dice:

—Rehúso matarlo, señor presidente.

— ¿Rehúsa matarme?

El presidente se lanza sobre Justina y la zarandea como el maniquí que simula ser:

— ¡Justina, solo tú me has sido fiel! ¿Qué quieres? ¿Qué necesitas para no rehusarte? - le dice. Y le promete que nadie castigará su crimen. Le ofrece casas en Miami, millones en cuentas de las islas Caimanes, un marido dispuesto a soportar sexo con un maniquí que no encorva la espalda, ¡lo que quiera!

Con el gesto impávido, Justina le dice:

-Ofrézcame, pero el sistema no quiere nada. Intente sobornarnos más tarde, señor presidente.

El presidente pierde el control que se ha estado guardando por mucho tiempo. Abofetea a Justina, le pega con el puño también y se da cuenta de que Justina no sangra, no se queja. La piel está firme, tan tersa como siempre o más tersa que nunca porque entonces lo nota. Justina no tiene ni una arruga. No le ha salido ni una arruga en los últimos tres sexenios de su gobierno.

—Pégueme — le dice - , pero al sistema no le duele. Intente reprimirnos más tarde, señor presidente.

Díez siente que algo está roto. Se restriega los ojos, mira al cielo y descubre algo que no sabe por qué ha tardado tanto tiempo en elucidar con certeza.

No hay sol. Nunca ha habido ningún sol en el cielo. Lo que hay es un globete, una pelotita de tenis amarilla colgada de un hilito transparente. Una carnada para que los incautos como Díez cayeran en la trampa. Detrás de la patética pelota y, sobre un cielo como de papel aluminio, sí: está el relojito de Windows, dando vueltas y anunciando que la realidad nunca terminará de coagularse para los habitantes de ese mundo.

—¿Qué le hicimos al país, Justina? —le pregunta. 
No tiene caso. Díez mira a su secretaria y siente la verdad en ese cuello doblado en un ángulo perfecto de cuarenta y cinco grados, en esa sonrisa de polígono que fue programada para tranquilizarlo.

- Shh. Todo estará bien, señor presidente.

La sonrisa negra de Justina abre las alas para envolverlo.

Como último recurso, Díez mira el cielo con ansias, esperando que en cualquier momento aparezca un letrero que diga Unexpected error. La aplicación se cerrará. Windows es incapaz de recuperarse.

No aparece, así que a Díez le tiembla la mano, pero se apunta con el revólver a la sien y se dispara.

Se escucha un ruido, pero no hay sangre, no hay dolor. No pasa nada.

La bala se rehúsa a que Díez deje de ser el presidente. 